\title{
Praat-Assisted Nasalance Meter:A Low-Cost Nasalance Measurement System for Evaluation of Nasal Resonance Disorders
}

\section{Praat Yardımlı Nazalans Ölçer: Nazal Rezonans Bozuklukların Değerlendirilmesinde Kullanılabilecek Düşük Maliyetli Bir Nazalans Ölçüm Sistemi}

\author{
๑ Mehmet Akif Kılıç ${ }^{1}, \oplus$ Ozan Tüysüz², • Fatih Mehmet Hanege², • Ceki Paltura³ \\ ${ }^{1}$ University of Health Sciences Turkey, İstanbul Ümraniye Training and Research Hospital, Clinic of ENT, Istanbul, Turkey \\ ${ }^{2}$ Istanbul Medeniyet University Faculty of Medicine, Department of Otorhinolaryngology, Istanbul, Turkey \\ ${ }^{3}$ Gaziosmanpaşa Training and Research Hospital, Clinic of Otorhinolaryngology, İstanbul, Turkey
}

Background: This study aimed to introduce a low-cost system measuring nasalance, which can often be performed with high-cost systems, and to present the normative nasalance values for adults using this system.

Materials and Methods: This study included 96 standard native Turkish-speaking literate volunteers who had no hearing and speech problems or nasal obstruction. Nasalance values were measured using the system developed by the principal author, which is called the praat-assisted nasalance meter, using speech materials and related methods.

Results: The participants were 18-65 (average, 33.7) years old. They were divided into three groups according to their age: 18-25, 26-40, and 41-65. A significant difference was found in the nasalance values between the genders. For nearly all speech materials, higher nasalance values were measured in women than in men.

Conclusion: There is no generally accepted rule to ascertain if a speaker's resonance is abnormal according to nasalance values. Therefore, the proposed threshold values should not be considered absolute values but should be decided with perceptual evaluation. Keywords: Nasal resonance, hypernasality, hyponasality, nasalance

Amaç: Bu çalışmanın amacı, genellikle yüksek maliyetli sistemlerle gerçekleştirilebilen nazalans parametresi ölçümü için kullanılabilecek kendi geliştirdiğimiz düşük maliyetli bir sistemi tanıtmak ve bu sistem kullanılarak erişkinler için belirlenen normatif nazalans değerlerini sunmaktır.

Gereç ve Yöntemler: Standart Türkiye Türkçesi konuşan ve okuma yazma bilen 96 gönüllü çalışmaya dahil edildi. Deneklerin işitme ve konuşma problemi, burun tıkanıklı̆ı yapan herhangi bir hastalığının olmamasına dikkat edildi. Birinci yazar tarafından geliştirilen ve Praat Yardımlı Nazalans Öıçer (PYNÖ) adı verilen sistem yardımıyla aşağıda belirtilen konuşma malzemesi ve yöntem kullanılarak nazalans ölçümü yapıldı.

Bulgular: Çalışmaya katılan 96 konuşmacının yaşları 18 ile 65 arasında değişiyordu (ortalama 33,7 yıl). Katııımcılar yaşlarına göre 18-25, 26-40 ve 41-65 şeklinde üç gruba ayrılarak incelendi. Elde edilen değerler cinsiyet grubuna göre karşılaştıııldığında aradaki farkların istatistiksel olarak anlamlı olduğu görüldü. Hemen her konuşma malzemesi için kadınlarda erkeklerden daha yüksek nazalans değerleri elde edildi.

Sonuç: Bir konuşmacı üzerinde ölçülen nazalans ölçüm sonuçlarının anormal olduğunu söylemek için genel kabul gören bir kural yoktur. Bu nedenle, bu çalışmada önerilen eşik değerler mutlak değerler olarak düşünülmemeli, algısal değerlendirmeyle birlikte karar verilmelidir.

Anahtar Kelimeler: Nazal rezonans, hipernazalite, hiponazalite, nazalans

\footnotetext{
Address for Correspondence: Mehmet Akif Kilç̧, University of Health Sciences Turkey, İstanbul Ümraniye Training and Research Hospital, Clinic of ENT, istanbul, Turkey Phone: +90 5323160184 E-mail: makilic@yahoo.com ORCID ID: orcid.org/0000-0003-0706-7032

Received: 19.08.2021 Accepted: 14.10.2021
} 


\section{Introduction}

Resonance is changing the frequency spectrum of the waves (particularly aerodynamic and acoustic ones) applied to an object or space; amplitude increases in some frequency regions and decreases in others.

As regards speech production, resonance is the change in the vocal tract of the source that occurs at the glottic level. In addition to determining the personal characteristics of the voice, resonation has an effect on the articulation of speech sounds, especially vowels. Resonance in the vocal tract is determined by the shape and size of the pharyngeal, oral, and nasal cavities, conditions of the mucous membrane covering the inner surface of these cavities, and tonus of the surrounding muscles. Problems with each of these cavities or changing of oral-nasal balance due to dysfunction or malfunction of the velopharyngeal valve will cause abnormal resonation. Resonance disorders are classified as nasal resonance disorders and oropharyngeal (oral and pharyngeal) resonance disorders (1).

Nasal resonance disorders, such as hypernasality, hyponasality, and mixed nasality, are important clinical conditions because of their potential association with morbidity. Hypernasality may be a consequence of velopharyngeal dysfunction or oronasal fistula, which may be or not accompanied by nasal air emission. Hyponasality is generally caused by nasal cavity obstruction (such as spaceoccupying lesions of the nasal cavity or nasopharynx,structural stenosis, and mucosal edema), or rarely by velopharyngeal malfunction. By contrast, mixed nasality is usually seen in a narrow but unchanging velopharyngeal port. Hypernasality is perceived during the production of vowels and voiced oral consonants, and hyponasality is perceived during the production of nasal consonants and adjacent vowels.

\section{Evaluation of Nasal Resonance Disorders}

Formant frequencies and bandwidths of the vowels, first and second nasal formant amplitudes (P0 and P1), acoustic parameters such as A1-P0, A1-P1, and voice low tone to high tone ratio, and nasalance are used to assess nasality $(1,2,3)$. Nasalance is the most reliable parameter to assess nasality and it is measured by the ratio of nasal-derived energy emerging during speech to oral/laryngeal energy.

\section{Nasalance $=\frac{\text { Nasal acoustic energy }}{\text { Nasal+Oral acoustic energy }} \times 100$}

For nasalance measurement, energy recording is made in three ways: acoustic, mechanoacoustic, and aerodynamic. In the acoustic method, which is the most widely used one, the nasal and oral sound pressure levels are recorded using a dual-headed stereo microphone. In the mechanoacoustic method, vibrations are recorded with accelerometers placed on the nose wings and larynx. In the aerodynamic method, the volume speed and pressure of air coming out of the nose and mouth are measured using special masks and sensors (4).

Acoustic nasalance measurements can be carried out with the software/hardware systems originally developed by Fletcher and Bishop (5) and currently produced by Pentax Medical (Nasometer), Tiger DRS, Inc. (Nasal View), Glottal Enterprises (NAS System), and Wevosys (lingWAVES Nasality). The hardware of these devices consists of two microphones mounted on a separator plate and head attachments to keep them in a horizontal position on the upper lip, or handle to hold it manually, and an audio interface that allows computer processing by turning sound pressure signals into numeric data.

Sound pressure signals are amplified before being processed on the computer (preamplification), and the band is filtered with a band-pass filter. Then, the nasalance value is derived by calculating the ratio of nasal and oral energy according to the aforementioned formula. Since measurement results can be affected by various factors, it is not possible to provide a universal nasalance value that shows the physiological pathological limit. Measurement results can be affected by the hardware/software features, calibration of the system used, hardware-speaker relationship that changes depending on the anatomical characteristics of the speaker or user, recording environment, physiological characteristics of the speaker, language/dialect spoken, and speech material.

With the background above, this study aimed to introduce a low-cost system measuring nasalance, which can often be performed with high-cost systems, and to present the normative nasalance values determined for adults using this system.

\section{Material and Methods}

\section{Subjects}

The study included 96 standard native Turkishspeaking literate volunteers aged 18-65 years (38 male, 58 female), who had no hearing and speech problems or nasal obstruction. Nasalance values were measured using the system developed by the principal author, which is called the praat-assisted nasalance meter (PANM), using the speech materials and methods specified below. This study was approved by İstanbul Medeniyet University Hospital, Scientific Research Ethics Committee (2018/0312). An informed consent form was obtained from all patients. 


\section{PANM}

PANM consists of hardware and software similar to other systems measuring nasalance. The hardware has four parts, namely, (1) separator plate, (2) earbuds functioning as microphones, (3) handle, and (4) audio interface (Figure 1).

1. Separator plate: It functions by separating signals coming out of the nose and mouth. A participant holds a PANM device above the vermillion border (Figure 2). It was

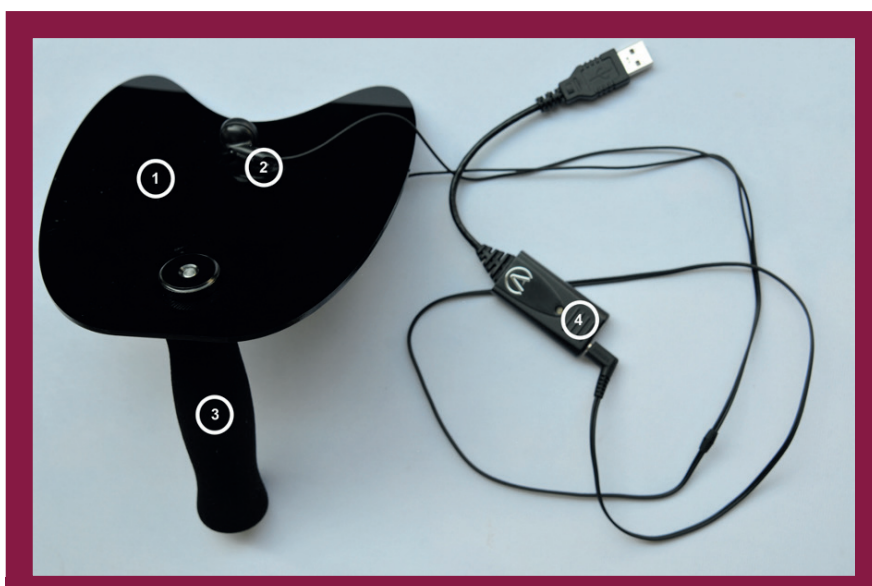

Figure 1. Praat-Assisted Nasalance Meter hardware: (1) Separator plate, (2) Earbuds (left/nasal channel), (3) Handle and thumb nut, (4) Audio interface

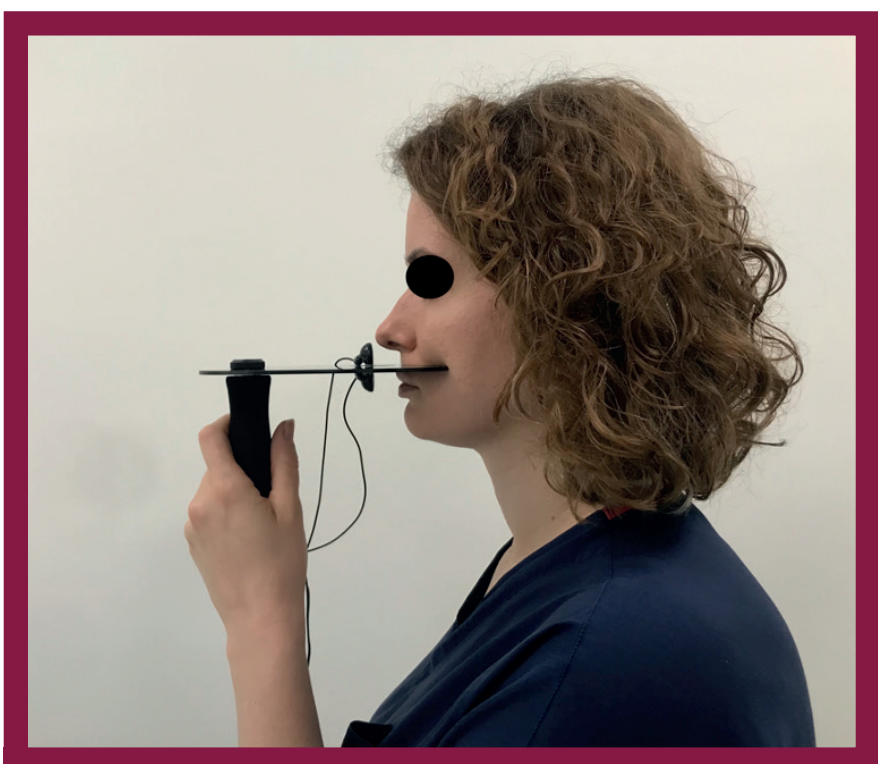

Figure 2. A participant holding a Praat-Assisted Nasalance Meter device above the vermillion border. The edge that comes into contact with the upper lip is concave so that there is no gap in between. There is a small line showing the middle line with an oval hole $21 \mathrm{~mm}$ away from this edge so that microphones can be easily placed in the appropriate position. The second hole at the other end of the plate with a diameter of $7 \mathrm{~mm}$ is for the handle to be mounted. made by $3 \mathrm{~mm}$-thick plexiglass sheet, using a computer numerical control cutting machine through the real-sized drawing file found at https://bit.ly/2UWjzwl.

2. Earbuds: Dynamic headphones function as dynamic microphones when they are connected to the audio interface through the microphone input (6). Philips SHE1350 (Koninklijke Philips Electronics N.V., Netherlands) earbuds were used instead of microphones for audio recording to reduce costs and were glued on to the separator plate placed $20 \mathrm{~mm}$ away from the concave edge in a way that the left channel was placed above and right channel was placed below. Instead of the Philips SHE1350, other earbuds with a diaphragm diameter of approximately $15 \mathrm{~mm}$ and a resistance of $32 \Omega$ can also be used.

3. Handle and thumb nut: They are mounted on the separator plate by the round hole on it to make it easier to hold the hardware.

4. Audio interface: Andrea USB-SA (Andrea Communications, USA) audio interface was preferred because it allows stereo audio recording, and it can attach to the 3.5 $\mathrm{mm}$ TRS microphone input without requiring an adapter.

The software side of PANM consists of the Praat (7) (free software for acoustic analyses) and the script written for it. This script and the customized Praat software, with which it is embedded, can be accessed at https://bit.ly/2Xt608x.

\section{Speech Material}

The speech material recommended by Oguzhan (8) for Turkish was modified and used in this study. The display of the speech materials in Turkish alphabet was provided in two angle brackets, while the representation in International Phonetic Alphabet was provided in two square brackets.

\section{Isolated Speech Sounds:}

1. Prolonged $\langle\mathrm{m}\rangle$ consonant, [m:.:.]

2. Prolonged $\langle\mathrm{a}\rangle$ vowel, [a:.:.]

Words (in a carrier sentence 〈Ahmet .... dedi〉):

1. The bilabial nasal consonant in the [a] vowel context: $\langle a m a\rangle,[\mathrm{ama}]$ (pre- or post-nasal consonantal vowel)

2. The dental nasal consonant in the [a] vowel context: 〈ana〉, [ana]

Nasalance values were measured over $1 / 3$ mid-region of the pre- (PreV) and post-consonantal vowels in the neighboring of both nasal consonants (PostV). In the text, the abbreviation PV refers to both PreV and PostV.

\section{Sentences:}

1. The Oral Plosive Sentence (OPS): 〈Petek, kırık tahta kapıyı kapattı.), [petec kuruk tahta kapuju kapat:u]

2. The Oral Sibilant Sentence (OSS): 〈Seçil, sıcak havuzda 
sessizce yüzdü.), [sєtfil sudłak havuzda ses:izḑॄ jyzdy]

3. The Nasal Sentence (NS): 〈Annem, Emine'ye ninni mırıldandı. $\rangle$, [an: $\varepsilon m$ emincje nin:i muruitdandw]

4. The Standard Reading Passage (SRP): 〈Dar kapisından başka aydınlık girecek hiçbir yeri olmayan dükkanında, tek başına, gece gündüz, kıvılcımlar saçarak çalışan Koca Ali, tıpkı kafese konmuş terbiyeli bir aslanı andırıyordu. $\rangle$, [daı kapusundan bajka ajduntuk jiredzec hitf bi. jeri ołmajan

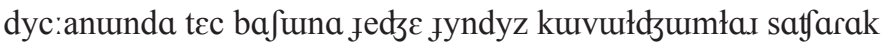

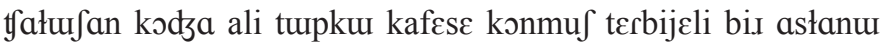
andurujo.ıdu]

\section{Calibration}

For accurate measurements with PANM, the recording sensitivity and frequency response of both channels of the microphone must be equal or very close to each other. Therefore, before the microphones (earbuds) are glued to the separator sheet, audio recording is carried out using SRP, while both head of the earbuds are held at an equal distance from the lips $(2-3 \mathrm{~cm})$. Nasalance values measured as described below on the recording are expected to be between $45 \%$ and $55 \%$. If values exceeding these limits are obtained, microphones should not be used in the PANM assembly.

After the installation of PANM is completed, the following operations are performed respectively.

1. Three recordings are performed on the same speaker using prolonged $\langle\mathrm{m}\rangle$ consonant and OPS by the nose pinched by fingers.

2. Then, the separator plate is reversed, replacing the microphones, and recording is repeated.

3. Nasalance measurement is made on the recordings. When analyzing recordings obtained with the reversed plate, the nose and mouth channels should be interchanged on the form.

4. Nasalance values should be higher than $90 \%$ for the prolonged $\langle\mathrm{m}\rangle$ consonant and lower than $10 \%$ for the OPS.

5. The difference between the initial measurement results and measurements made after the microphones are replaced must be lower than $5 \%$.

\section{Measurements}

After the PANM was placed horizontally on the upper lip's vermillion border of the speaker sitting upright, the speaker was asked to utter the above-mentioned speech material. Using Audacity (9) software, signals from the nose were recorded in the left channel and signals from the mouth were recorded in the right channel in stereo. During recording, the amplitude of sound waves was not lower than $-35 \mathrm{dBFS}$, and they were not allowed to exceed
$-3 \mathrm{dBFS}$, except for oral plosives. Audio files were opened in the Praat software to mark the location of the speech materials; TextGrid files were created and saved. Using the PANM script, nasalance values were measured separately for each material. Isolated speech sounds and sentences were segmented in one piece, and single measurements were made for each piece. Segmentation of the words was performed at the speech sound (vowel before the nasal consonant, vowel after the nasal consonant) level. On the form of the script, the "tpnum" value was selected as 3 , and three separate measurements were made for each segment, i.e., initial, middle, and final.

\section{Statistics Analysis}

SPSS version 23.0 (IBM Corp. Released 2015. IBM SPSS Statistics for Windows, Version 23.0. Armonk, NY: IBM Corp.) was used for statistical analysis. The Shapiro-Wilk and Kolmogorov-Smirnov tests were used to determine whether data distribution was normal. Gender and age groups were compared using a t-test or Mann-Whitney $\mathrm{U}$ test, depending on the data distribution (normal or not normal). A p-value of $<0.05$ was considered significant.

\section{Results}

The average age of the 96 participants (38 male, 58 female) was 33.7 years. The speakers were divided into three age groups: $18-25,26-40$, and 41-65 groups.

A significant difference was found in the nasalance values between the genders. Women had higher nasalance values for almost every speaking material than men had. Although comparisons by age groups showed a difference between some speech materials, it was not included in the evaluation to avoid complexity. Nasalance values measured without gender discrimination are shown in Table 1, and nasalance values measured by gender discrimination are shown in Table 2 and 3.

\section{Determination of Border Values}

Normonasality-hypernasality values were determined by adding twice the standard deviation (SD) to mean nasalance values of speech materials used for determining hypernasality, and hyponasality-normonasality border values were determined by subtracting twice the SD from mean nasalance values of speech materials used to determine hyponasality. This method is similar to the Kummer's method but is slightly different. Kummer (10) used standard deviation when determining the threshold value for simplified nasometric evaluation procedure test and accepted 2 SD above the average value for oral speech material and 1 SD below nasal speech material as a threshold value.

According to values obtained without gender 
discrimination, nasalance values of $>27 \%$ for OPS, $>46 \%$ for OSS, $>67 \%$ for SRP, and $>75 \%$ for PV were considered hypernasality. By contrast, values of $<64 \%$ for NS, $<24 \%$ for SRP, and $<25 \%$ for PV were considered hyponasality. To suggest more memorable values, values higher than $25 \%$ for OPS and $45 \%$ for OSS are considered hypernasality, and values lower than $65 \%$ for NS are considered hyponasality (Table 4).

Table 1. Identifying the statistical results of nasalance values measured without gender discrimination

\begin{tabular}{|l|l|l|l|l|l|}
\hline Purpose & Material & M & SD & Min & Max \\
\hline \multirow{3}{*}{ Calibration } & NC- OPS & 2.7 & 1.7 & 0.7 & 8.2 \\
\cline { 2 - 6 } & {$[\mathrm{m}::]$.} & 96.6 & 2.3 & 90.2 & 99.7 \\
\hline \multirow{3}{*}{ Hypernasality } & OPS & 12.8 & 7.1 & 3.7 & 39.1 \\
\cline { 2 - 6 } & OSS & 23.4 & 11.2 & 6.2 & 54.7 \\
\hline Hyponasality & NS & 76.4 & 6.4 & 61.7 & 89.6 \\
\hline \multirow{3}{*}{$\begin{array}{l}\text { Hypernasality/ } \\
\text { hyponasality }\end{array}$} & SRP & 45.5 & 10.6 & 23.0 & 68.3 \\
\cline { 2 - 6 } & PreV & 50.1 & 13.0 & 14.9 & 82.8 \\
\cline { 2 - 6 } & PostV & 49.3 & 12.0 & 23.4 & 78.8 \\
\hline
\end{tabular}

M: Mean, SD: Standard deviation, Min: Minimum value, Max:

Maximum value, (NC-OPS: Nose-closed oral plosive sentence, [m::.]: Prolonged $<\mathrm{m}>$ consonant, OPS: Oral plosive sentence, OSS: Oral sibilant sentence, NS: Nasal sentence, SRP: Standard reading passage, PreV: $1 / 3$ mid-region section of the vowel [a] before the consonant in the nasal word, PostV: $1 / 3$ mid-region of the vowel [a] after the consonant in the nasal word

Table 2. Identifying the statistical results of nasalance values measured in women

\begin{tabular}{|l|l|l|l|l|l|}
\hline Purpose & Material & M & SD & Min & Max \\
\hline \multirow{3}{*}{ Calibration } & NC- OPS & 2.4 & 1.7 & 0.7 & 8.2 \\
\cline { 2 - 6 } & {$[\mathrm{m}: .:]$} & 97.2 & 1.9 & 92.3 & 99.7 \\
\hline \multirow{3}{*}{ Hypernasality } & OPS & 15.1 & 7.7 & 3.7 & 39.1 \\
\cline { 2 - 6 } & OSS & 27.4 & 11.1 & 11.6 & 54.7 \\
\hline Hyponasality & NS & 78.7 & 6.1 & 63.9 & 89.6 \\
\hline \multirow{3}{*}{$\begin{array}{l}\text { Hypernasality/ } \\
\text { hyponasality }\end{array}$} & SRP & 50.0 & 10.2 & 25.2 & 68.3 \\
\cline { 2 - 6 } & PreV & 52.3 & 13.6 & 18.6 & 83.0 \\
\cline { 2 - 6 } & PostV & 51.9 & 12.1 & 25.4 & 78.8 \\
\hline
\end{tabular}

M: Mean, SD: Standard deviation, Min: Minimum value, Max: Maximum value. (NC-OPS: Nose-closed oral plosive sentence, [m::.:]: Prolonged $\langle\mathrm{m}\rangle$ consonant, OPS: Oral plosive sentence, OSS: Oral sibilant sentence, NS: Nasal sentence, SRP: Standard reading passage, PreV: $1 / 3$ mid-region section of the vowel [a] before the consonant in the nasal word, PostV: $1 / 3$ mid-region of the vowel [a] after the consonant in the nasal word

\begin{tabular}{|c|c|c|c|c|c|}
\hline Purpose & Material & $M$ & SD & Min & Max \\
\hline \multirow[t]{2}{*}{ Calibration } & NC-OPS & 3.0 & 1.7 & 0.8 & 6.7 \\
\hline & {$[\mathrm{m}::]$} & 95.8 & 2.6 & 90.2 & 99.7 \\
\hline \multirow[t]{2}{*}{ Hypernasality } & OPS & 9.8 & 4.9 & 3.7 & 25.9 \\
\hline & OSS & 18.1 & 8.9 & 6.2 & 37.1 \\
\hline Hyponasality & NS & 73.3 & 5.3 & 61.7 & 83.6 \\
\hline \multirow{3}{*}{$\begin{array}{l}\text { Hypernasality/ } \\
\text { hyponasality }\end{array}$} & SRP & 39.7 & 8.2 & 23.0 & 52.2 \\
\hline & PreV & 46.9 & 11.3 & 14.9 & 69.9 \\
\hline & PostV & 45.4 & 10.7 & 23.4 & 68.8 \\
\hline
\end{tabular}

M: Mean, SD: Standard deviation, Min: Minimum value, Max: Maximum value. (NC-OPS: Nose-closed oral plosive sentence, [m::.: : Prolonged $\langle\mathrm{m}\rangle$ consonant, OPS: Oral plosive sentence, OSS: Oral sibilant sentence, NS: Nasal sentence, SRP: Standard reading passage, PreV: $1 / 3$ mid-region section of the vowel [a] before the consonant in the nasal word, PostV: $1 / 3$ mid-region of the vowel [a] after the consonant in the nasal word

Table 4. Average, standard deviation and cut-off values of nasalance values measured without gender discrimination

\begin{tabular}{|l|l|l|l|l|l|}
\hline Purpose & Material & M & SD & M - 2×SS & M + 2×SS \\
\hline \multirow{2}{*}{ Hypernasality } & OPS & 12.8 & 7.1 & -1.4 & 27 \\
\cline { 2 - 6 } & OSS & 23.4 & 11.2 & 1 & 45.8 \\
\hline Hyponasality & NS & 76.4 & 6.4 & 63.6 & 89.2 \\
\hline $\begin{array}{l}\text { Hypernasality/ } \\
\text { hyponasality }\end{array}$ & SRP & 45.5 & 10.6 & 24.3 & 66.7 \\
\cline { 2 - 6 } & PV & 49.7 & 12.5 & 24.7 & 74.7 \\
\hline
\end{tabular}

OPS: Oral plosive sentence: OSS: Oral sibilant sentence: NS: Nasal sentence: SRP: Standard reading passage: PreV and PostV values in the preceding tables are combined because they are close together. Pay attention to the values in the columns of $M+2 \times S D$ for the hypernasality group: values in the $M-2 \times S D$ columns for the hyponasality group, and the values in both columns for the hypernasality/hyponasality group. PV, PreV and PostV together

\section{Discussion}

Subjective (perceptual) and objective (instrumental) evaluation methods are used in the evaluation of nasal resonance disorders, as in voice disorders. Subjective evaluation is very difficult to standardize, while it yields reliable results when performed with well-trained ears.

In practice, although the level of nasal resonance disorder is misinterpreted, situations in which hypernasality is interpreted as hyponasaltity or hyponasality as hypernasality are frequently encountered. Therefore, in the evaluation of patients who are thought to have a nasal resonance disorder, objective methods such as nasalance measurement must be used and a decision should not be made using a single method.

As mentioned in the introduction, nasalance values are affected by various factors. The normative values set for one device do not apply to another device. Therefore, 
separate standardization work is required for each device. Awan and Virani (11) noted possible significant differences even between two versions of the system produced by the same company. Changing any component of the PANM used in this study (e.g., the earbuds used as a microphone) will affect nasalance values naturally.

Considering other factors such as recording environment, language, and dialect, a normative assessment work on a small group before using a newly acquired nasalance meter device on patients could be the right approach. In this way, the speech material used in the study with the language/dialect spoken in the hinterland of that clinic should be tested as well. Other factors, such as gender and age, can also affect nasalance. Studies have reported higher values in women than in men besides those reporting no difference between genders $(12,13,14)$. Since this study was carried out to introduce a newly developed device and to determine normative values related to it, the differences were not emphasized.

In this study, the borders between normonasality and hypernasality, and hyponasality and normonasality were determined 2 SD above the mean value for oral speech material and 2 SD below the mean value for nasal speech material. However, a wide gray area exists between normal and abnormal nasal resonance, so it is difficult to determine a clear nasalance threshold value.

\section{Conclusion}

There is no generally accepted rule to ascertain that a speaker's resonance is abnormal based on nasalance values. Therefore, the proposed threshold values should not be considered absolute values but should be decided with perceptual evaluation. For every clinician (a physician or speech therapist), acquiring a new nasalance measurement system on a small group of subjects would be of great benefit to determine individual normative values.

\section{Ethics}

Ethics Committee Approval: This study was approved by İstanbul Medeniyet University Hospital, Scientific Research Ethics Committee (2018/0312).

Informed Consent: An informed consent form was obtained from all patients.

Peer-review: Externally and internally peer-reviewed.

\section{Authorship Contributions}

Surgical and Medical Practices: M.A.K., O.T., C.P., Concept: M.A.K., O.T., F.M.H., C.P., Design: M.A.K., O.T., F.M.H., C.P.,
Data Collection or Processing: M.A.K., O.T., C.P., Analysis or Interpretation: M.A.K., O.T., C.P., Literature Search: M.A.K., O.T., F.M.H., C.P., Writing: M.A.K., O.T.

Conflict of Interest: No conflict of interest was declared by the authors.

Financial Disclosure: The authors declared that this study received no financial support.

\section{References}

1. Kılıç MA. Nasal and oro-pharyngeal resonance disorders, Kaynak Kitap-2. İçinde: Yigit O, Kara CO, Alkan Z, editors. Kulak Burun Bogaz ve Baş Boyun Cerrahisi Egitimi. İstanbul: Logos Publishing; 2019:617-621. (Turkish). [Crossref]

2. Lee AS, Ciocca V, Whitehill TL. Acoustic correlates of hypernasality. Clin Linguist Phon. 2003;17:259-264. [Crossref]

3. Lee GS, Wang CP, Fu S. Evaluation of hypernasality in vowels using voice low tone to high tone ratio. Cleft Palate Craniofac J. 2009;46:47-52. [Crossref]

4. Rothenberg M, Mask-Based Nasometry A New Method for the Measurement of Nasalance, 2020,Available from: http://www.rothenberg. org/Nasalance/Nasalance.htm. [Crossref]

5. Fletcher SG, Bishop ME. Measurement of nasality with tonar. Cleft Palate J. 1970;7:610-621. [Crossref]

6. Ostdiek VJ, Bord DJ. Electromagnetism and EM waves. In: Inquiry Into Physics (7th Edition) Boston: Brooks/Cole; 2013, s.292-335. [Crossref]

7. Boersma P, Weenink D. Praat: doing phonetics by computer [Computer program]. Version 6.1.33, Last Accessed Date: 19.11.2020. Available from: http://www.praat.org/. [Crossref]

8. Oğuzhan O. Determination of Normal Nasalance Values for Turkish. Dissertation Thesis. Kahramanmaraş: Kahramanmaraş Sütçü Imam University Department of Otorhinolaryngology, Faculty of Medicine; 2013. (Turkish). [Crossref]

9. Audacity Team (2021). Audacity(R): Free Audio Editor and Recorder [Computer application]. Version 3.0.0. Last Accessed Date: 17.04.2021. Available from: https://audacityteam.org/. [Crossref]

10. Kummer AW. The MacKay-Kummer SNAP Test-R Simplified Nasometric Assessment Procedures (Revised 2005). doi:10.13140/2.1.2614.6080 [Crossref]

11. Awan SN, Virani A. Nasometer 6200 Versus Nasometer II 6400: Effect on Measures of Nasalance. Cleft Palate Craniofac J. 2013;50:268-274. [Crossref]

12. Seaver EJ, Dalston RM, Leeper HA, Adams LE. A study of nasometric values for normal nasal resonance.J Speech Hear Res. 1991;34:715-721. [Crossref]

13. Litzaw LL, Dalston RM. The effect of gender upon nasalance scores among normal adult speakers. J Commun Disord. 1992;25:55-64. [Crossref]

14. Hirschberg J, Bók S, Juhász M, Trenovszki Z, Votisky P, Hirschberg A. Adaptation of nasometry to Hungarian language and experiences with its clinical application. Int J Pediatr Otorhinolaryngol. 2006;70:785-798. [Crossref] 